\title{
Heat Resistant Building Envelopes Made of Lightweight Concrete with the use of Porous Granular Wastes
}

\author{
Galitskov S.Ya., Mizuryaev S.A., Chiknovoryan A.G. \\ Samara State Technical University, Institute of Architecture and Civil Engineering \\ Address: Molodogvardeyskaya St., 194, Samara, 443001, Russia
}

\begin{abstract}
The paper focuses on building envelopes for industrial thermal generating units, their efficiency and its increase. Building envelopes made of lightweight heat-resistant concretes are considered most effective from the point of their building construction, maintenance, repair and cost-effectiveness. One of the unresolved problems here is that porous granular materials suitable for use as concrete fillers operating at temperatures over $1000^{\circ} \mathrm{C}$ are not industrially manufactured at the moment The article also characterises commonly used heat resistant porous fillers. It indicates that the use of exhaust zeolites is potentially perspective General properties and characteristics of zeolites are also given. The paper demonstrates that it is quite possible to use exhaust zeolites in building envelopes of lightweight heat-resistant concretes. The work describes testing experiments of typical exhaust zeolites (petrochemical and oil refining industries wastes) in Samara region and the Republic of Tatarstan. Their stress-strain properties and chemical compositions as well as X-ray crystallographic analysis (including analysis under high temperature) are presented. They prove that zeolites are heat-resistant and fire-proof because of corundum formation. Phosphate binder was used for tesing in heat-resistant concretes. The composition of the concrete mixture is given in the paper. As a result, concrete with the following characteristics was obtained: $1550 \mathrm{~kg} / \mathrm{m}^{3}$ density, with compressive strength of approximately $21 \mathrm{MPa}$, having high thermal resistance and maximum permissible application temperature of $1450^{\circ} \mathrm{c}$.
\end{abstract}

Keywords: lightweight concretes, heat resistance, exhaust zeolites, concrete mixture, physical and thermal properties.

\section{INTRODUCTION}

Nowadays hardly any production can do without thermal units of different application, for which the most effective lining is usually constructions of lightweight heat-resistant concrete. Nevertheless, the overall volume of concrete linings compared to single-piece refractories, is extremely small and is less than $10 \%$ of the total. One of the reasons here is the lack of industrial production, i.e. large quantity production of heat-resistant porous fillers for concrete, which are able to work at a temperature over $1000{ }^{\circ} \mathrm{C}$ [1-5]. Such porous fillers as expanded clay, ceramsite, aggloporite, vermiculite, perlite are sometimes referred to as heat-resistant, but their maximum application temperature does not exceed $1000-1100{ }^{\circ} \mathrm{C}$. It is important to note that several types of heat-resistant porous fillers as well as the technology for their production have already been invented for concretes used at temperatures 1000$1500{ }^{\circ} \mathrm{C}$ [5-13]. The methodology of producing such aggregates is based on very scarce and expensive high-aluminous raw materials and their clinker formation, melting and swelling at high temperatures. Therefore, searching and discovering of available porous, preferably granulated, materials with high fire resistance is now of considerable interest.

\section{THEORY AND EXPERIMENTS}

Some of the most promising materials, in terms of their use as heat-resistant fillers, are exhausted zeolite-containing adsorbents which are wastes of petrochemical industry and oil refining factories.

Such materials include exhaust zeolites, zeasorbs and other zeolite-like catalysts, hereinafter referred to as "zeolites".

Zeolites are referred to the class of hydroalumosilicates with space-framed structure. Such tetrahedra as $\mathrm{AlO}_{4}$ or $\mathrm{SiO}_{4}$ with negative charges balanced by $\mathrm{Ca}, \mathrm{Mg}, \mathrm{Na}, \mathrm{K}$ and sometimes $\mathrm{Ba}$ or $\mathrm{Sr}$ ions serve as the basis of the frame. All zeolites have one and the same typical structure: their crystal lattice is penetrated by micropores of a certain size, enabling anions and cations move to the center of the structure, or, vice versa, to its periphery [14-16].

Wide application of zeolites in petrochemical and refining industries is brought about by the following characteristic properties:

a) zeolites are "cations", i.e. capable of ion exchange of cations with surrounding environment. This characteristic makes possible to use them for regulating water hardness; 
b) a definite diameter of zeolite pores can be used for gaseous and liquid substances clearance from various impurities or for separation of substances with different size of their molecules. Therefore, zeolites are often referred to as "molecular sieves";

c) the volumes of zeolite-containing wastes are quite substantial. According to our information, 2-3.5 thousand tons of such zeolite-containing wastes are generated only in the Samara region. Almost all of these exhaust zeolites look as granules of 1-8 mm size with the bulk density up to $850 \mathrm{~kg} / \mathrm{m}^{3}$ and refractory property of $1550-1800{ }^{\circ} \mathrm{C}$.

Research and testing of exhaust zeolites generated by industrial enterprises of Samara region (Z-1) and the Republic of Tatarstan (Z-2) were carried out in accordance with standard methodologies and the Standard of the Russian Federation № 20955 "Heatresistant concretes and their aggregate and fillers". The influence of high-temperature heating on these wastes was studied by means of X-ray crystallographic analysis.

Physical and mechanical characteristics of exhaust zeolites are presented in Table 1.

Table I

Physical mechanical properties of used adsorbents

\begin{tabular}{|c|c|c|}
\hline \multirow{3}{*}{ Indicators } & \multicolumn{2}{|c|}{ Value of indicators } \\
\hline & \multicolumn{2}{|c|}{ Zeolite type } \\
\hline & $\mathrm{Z}-1$ & $\mathrm{Z}-2$ \\
\hline \multicolumn{3}{|l|}{ Density: } \\
\hline -absolute, $\mathrm{g} / \mathrm{cm}^{3}$ & 2.8 & 2.7 \\
\hline - in the lump, $\mathrm{g} / \mathrm{cm}^{3}$ & 1.18 & 1.37 \\
\hline - bulk, $\mathrm{kg} / \mathrm{m}^{3}$ & 640 & 810 \\
\hline \multicolumn{3}{|l|}{ Porosity: } \\
\hline - true, $\%$ & 58 & 49 \\
\hline - intergranular, \% & 46 & 41 \\
\hline $\begin{array}{c}\text { Water absorption by } \\
\text { weight, } \%\end{array}$ & 75 & 47 \\
\hline \multicolumn{3}{|l|}{ Sieve residue percentage, $\%$} \\
\hline $10 \mathrm{~mm}$ & 2.6 & 3.7 \\
\hline $5 \mathrm{~mm}$ & 77.4 & 88.8 \\
\hline $2.5 \mathrm{~mm}$ & 19.4 & 7.5 \\
\hline $1.25 \mathrm{~mm}$ & 0.6 & - \\
\hline $0.63 \mathrm{~mm}$ & - & - \\
\hline $0,315 \mathrm{~mm}$ & - & - \\
\hline $0,14 \mathrm{~mm}$ & - & - \\
\hline $\begin{array}{l}\text { Cylinder compressive } \\
\text { strength, MPa }\end{array}$ & 2.7 & 4.64 \\
\hline
\end{tabular}

According to their chemical composition (see Table 2), the zeolites in question are high-aluminous materials with a minimum content of fluxing oxides. This fact predetermines their high refractory properties.
Table 2

Physical mechanical properties of used adsorbents

\begin{tabular}{|c|c|c|c|c|c|c|c|c|c|}
\hline \multirow[b]{2}{*}{ 兯 } & \multicolumn{9}{|c|}{ Oxide } \\
\hline & $\stackrel{0}{\infty}$ & 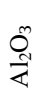 & 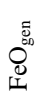 & 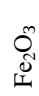 & $\begin{array}{l}0 \\
0 \\
1\end{array}$ & 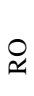 & రీ & $\begin{array}{l}0 \\
\\
\end{array}$ & $\hat{\hat{\imath}}$ \\
\hline Z-1 & $\stackrel{\leftrightarrow}{\dot{\gamma}}$ & ñ & $\begin{array}{l}\text { oे } \\
\text { r. }\end{array}$ & $\stackrel{\text { ñ }}{\text { ñ }}$ & $\exists$ & $\bar{n}$ & $\stackrel{m}{0}$ &  & $\stackrel{0}{i}$ \\
\hline Z-2 & $\underset{i n}{\stackrel{J}{n}}$ & $\begin{array}{l}0 \\
\stackrel{N}{N}\end{array}$ & ஜֶ? & $\begin{array}{l}n \\
n \\
n\end{array}$ & $\underbrace{+}_{-}$ & $\bar{n}$ & ڤ̊ & $\overline{0}$ & $\frac{\infty}{a}$ \\
\hline
\end{tabular}

X-ray crystallographic analysis made it possible to prove that tested exhaust zeolites at a temperature of $20{ }^{\circ} \mathrm{C}$ contain mostly boehmite $\gamma$-AlO $(\mathrm{OH})$ (see Figure 1). The analysis results prove the results of chemical composition of zeolites determinations and conclusions that high-aluminous compounds of high refractory properties make the large part of zeolites composition.

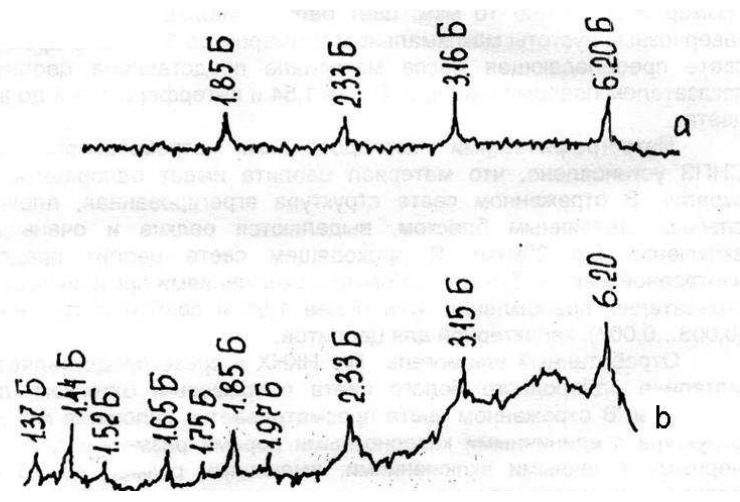

Fig. 1. X-ray diffraction pattern of exhausted adsorbents at $20^{\circ} \mathrm{C}$ : $\mathrm{a}-\mathrm{Z}-1 ; \mathrm{b}-\mathrm{Z}-2$

It goes without saying that heat resistant fillers for concrete should have certain physical and thermal characteristics. Physical and thermal characteristics of exhaust zeolites are presented in Table 3. For a comparative analysis we also give here similar characteristics of specially manufactured aggloporite (A) generated from high refractory raw charge with refractoriness of $1710 \ldots 1750{ }^{\circ} \mathrm{C}$.

The obtained data show that the wastes in question are similar by their physical and thermal properties to specially produced high-resistant aggloporite with very energy-consuming production technology. For the final determination of maximum permissible temperature of lightweight concrete application on tested zeolites we tested concretes to determine their deformation under load when heated. 
Table 3

Special physical and thermal properties of exhaust zeolites

\begin{tabular}{|c|c|c|}
\hline \multirow{2}{*}{$\begin{array}{c}\text { Zeolite } \\
\text { type }\end{array}$} & \multicolumn{2}{|c|}{ Indicators } \\
\cline { 2 - 3 } & $\begin{array}{c}\text { When heated to } 1000^{\circ} \mathrm{C} \\
\text { and cooled in air jet }\end{array}$ & $\begin{array}{c}\text { Fire Resistance, } \\
\text { O } \mathrm{C}\end{array}$ \\
\hline $\mathrm{Z}-1$ & 41 & 1750 \\
\hline $\mathrm{Z}-2$ & 46 & 1850 \\
\hline $\mathrm{A}$ & 25 & $1710-1750$ \\
\hline
\end{tabular}

For materials designed to operate at high temperatures, it is necessary have data on the nature of the processes occurring in these materials when heated. To do that we applied X-ray crystallographic analysis of exhaust zeolites Z-1 and Z-2 at temperatures of $300,500,800,1000$ and $1200{ }^{\circ} \mathrm{C}$. The results of the tests are given in Figures 2 and 3.

The results show that at a temperature of $300{ }^{\circ} \mathrm{C}$ the tested zeolites are presented as «bemites» AlO $(\mathrm{OH})$ (see Figures $2 \mathrm{a}$ and $3 \mathrm{a}$ ). When zeolites are heated to 500, 800 and $1000{ }^{\circ} \mathrm{C}$ they are dehydrated and amorphicized. At these temperatures they have only the traces of $\gamma$-alumina (see Figures $2 b, 2 c, 2 d$ and $3 b, 3 c, 3 d)$. When zeolites are further heated to $1200{ }^{\circ} \mathrm{C}$ they form corundum $\alpha-\mathrm{A}_{2} \mathrm{O}_{3}$ (see Figures $2 \mathrm{e}$ and $3 \mathrm{e}$ ). Corundum formation at high temperatures is beneficial, because it is a stable high temperature form of alumina that has high strength and thermal characteristics.

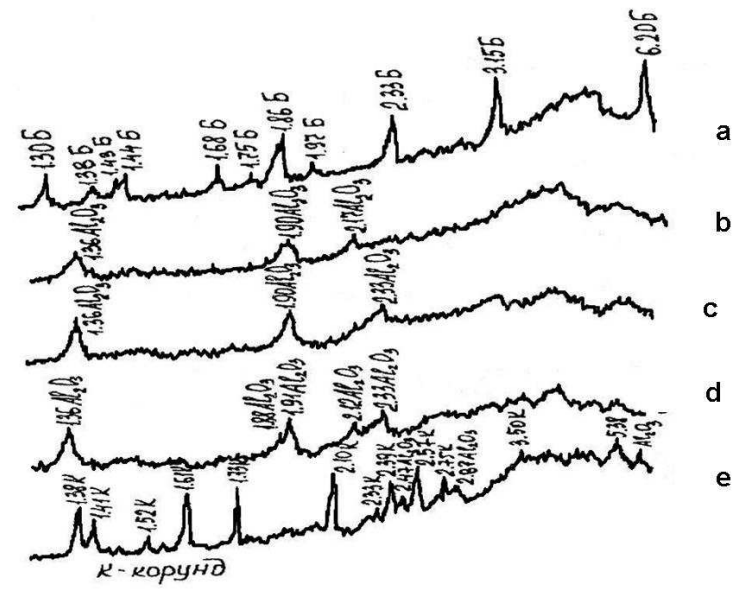

Fig. 2. Exhaust zeolite Z-1 X-ray diffraction pattern a - at 300; b - at 500; c - at 800; d - at 1000; e - at $1200^{\circ} \mathrm{C}$.

The analysis of the obtained results showed that for the manufacture of heat-resistant concretes the most effective binder (for the purpose of working together with the filler) is the phosphate binder based on phosphoric acid and floured chamotte.

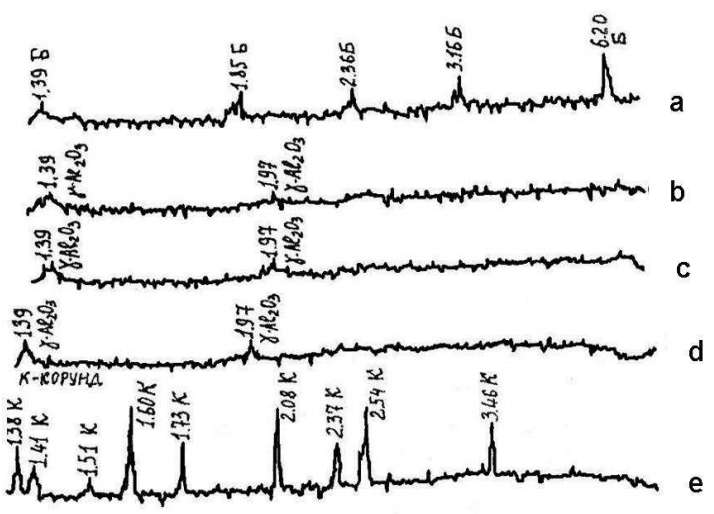

Fig. 3. Exhaust zeolite Z-2 X-ray diffraction pattern: a - at 300, $\mathrm{b}-$ at $500, \mathrm{c}-$ at $800 . \mathrm{d}-$ at $1000, \mathrm{e}-$ at $1200{ }^{\circ} \mathrm{C}$.

The analysis of the obtained results showed that for the manufacture of heat-resistant concretes the most effective binder (for the purpose of working together with the filler) is the phosphate binder based on phosphoric acid and floured chamotte.

In the course of the experiments the following composition of the concrete mix (for 1 cub.m. of concrete) was suggested:

- exhaust zeolites - $660 \mathrm{~kg}$;

- floured chamotte - $530 \mathrm{~kg}$;

- $65 \%$ orthophosphoric acid - 5601 .

As the result we obtained concrete with 1550 $\mathrm{kg} / \mathrm{m}^{3}$ density and with compressive strength of approximately $21 \mathrm{MPa}$. The designed lightweight heat-resistant concrete had the following thermal characteristics:

- heat resistance after heating to $800{ }^{\circ} \mathrm{C}$ is $45-55$ air thermal shifts;

- the maximum permissible temperature of use corresponding to $4 \%$ of deformation is $1450^{\circ} \mathrm{C}$.

\section{RESULTS}

The research yielded the following conclusions:

- Exhaust zeolites density makes it possible to refer them to aggregate and fillers suitable for manufacturing lightweight concrete. Exhaust zeolites are characterized by comparatively high compressive strength $(2.7 \ldots 4.6 \mathrm{MPa})$.

- According to their chemical composition, exhaust zeolites are high-aluminouscontaining materials (over $70 \%$ of $\mathrm{Al}_{2} \mathrm{O}_{3}$ ) with a minimum content of oxides of $\mathrm{RO}$ and $\mathrm{R}_{2} \mathrm{O}$.

- When exhaust zeolites are heated, they generate a high temperature form of alumina corundum - characterized by high heatresistant, strength and fire-resistant properties.

- The exhaust zeolites under analysis have high fire-resistant properties: $1750-1850{ }^{\circ} \mathrm{C}$.

- Characteristics exhaust zeolites correspond to the requirements of the Standard of the Russian Federation № 20955 "Heat-resistant concretes and their aggregate and fillers" and 
can be used as porous fillers in lightweight heat-resistant concretes.

- Heat-resistant lightweight concrete obtained on the basis of exhaust zeolites has excellent physical and thermal characteristics and is suitable for manufacturing structures, designed to operate at temperatures up to $1450{ }^{\circ} \mathrm{C}$.

\section{REFERENCES}

[1] Gorin V.M. Extension of the scope of ceramsite gravel usage. Construction materials, 11, 2003, pp. 19-21.

[2] Vytchikov Yu.S. Improving energy efficiency of buildings and facilities. Intercollegiate scientific paper,/Samara State University of architecture and civil engineering, 7, 2012, pp. 245-249.

[3] Balabanov M.S. Influence of aggregate properties on the properties of concrete. Collection of works. Samara State University of architecture and civil engineering, 2013, pp. 1314.

[4] Kudyakov A.I., Radina T.N., Ivanov M.Yu. Granular insulating material on the basis of modified water glass of microsilicasuspension. Construction materials, 11, 2004, pp. 12-13.

[5] Mizuriaev S.A., Zhigulina A.Yu., Mamonov A.N., Ivanova N.V. Expansion of nomenclature of synthetic porous fillers. Construction materials, 7, 2011, pp. 12-13.

[6] Galickov S.Ya., Galickov K.S., Samokhvalov O.V., Fadeev A.S. Simulation study ofceramsite burning in the rotating kiln with angular velocity as control object. Scientific Survey, 2015, pp. 227-237.

[7] A.Yu. Zhigulina, S. A. Mizyuryaev. Composition for production of porous filler, patent. 2003, No. 2211196 RU.
[8] S. A. Mizyuryaev, A.Yu. Zhigulin, Construction designs and materials. Express information, 16, 2002, pp. 1-3.

[9] Guryanov A.M., Mizuriaev S.A., Lebedev V.M., Lebedev V.T. Nanostructured porous materials on the basis of soluble sodium glass. Proceedings of the $V$ Eurasian scientificpractical Conference "Strength of non-homogeneous structures", 2010, pp. 136-137.

[10] Ivashchenko Yu.G., Surnin, A.A., Zobkova N.V., Pavlova I.L. Composition for manufacturing spherical granules for thermal insulation material, patent. 2000, No. 2158716RU.

[11] Korotayev S.A., Erofeev V.T. Obtaining lightweight concrete based on solid glassy binder. Bulletin of Mordovskiy University, 4, 2008, pp. 54-59.

[12] Kudyakov A.I., Radina T.N., Ivanov M.Yu. Granular insulating material on the basis of modified water glass of microsilicasuspension. Construction materials, 11, 2004, pp. 12-13.

[13] Mizuriaev S.A., Zhigulina A.Yu., Mamonov V.N. Development of an effective fire-resistant insulation of cellular structures. Industrial and civil engineering, 6, 2015, pp. 47-50.

[14] Kubasov A.A. Zeolites - boiling stones. Soros educational journal, Vol. 3, 5, 2006, pp. 58-65.

[15] Romanovskiy B.V., Makshina E. V. Nanocomposites as functional materials. Soros educational journal, Vol. 8, 2, 2004 , pp. 50-55.

[16] Konkova T.V., Lieberman E.Yu., Alekhina M.B., Pochitalkina I.A. Adsorption processes. Encyclopedia of engineer-chemist, 2, 2007, pp. 12-17. 